\title{
GIS Technology, 3D Models and Mathematical Models as a Tool for Assessing Development Capabilities of Flood Risk Land to Make Arrangements of Municipal Planning Documents
}

\author{
Anna Bazan-Krzywoszańska1* , Maria Mrówczyńska' ${ }^{1}$ Sławomir Tront ${ }^{3}$ \\ 1 Faculty of Civil Engineering, Architecture and Environmental Engineering, Institute of Civil Engineering, \\ University of Zielona Góra, prof. Z. Szafrana 1, 65-516 Zielona Góra, Poland \\ 2 P.A. Nova S.A., Górnych Wałów 42, 44-100 Gliwice, Poland \\ * Corresponding author's e-mail: A.Bazan@aiu.uz.zgora.pl
}

\begin{abstract}
With regard to the municipal spatial policies, the issue of flood protection, and hence the directions of development of flood-endangered land seem rather significant, given the possible social and economic consequences of a wrong decision. Currently, there is no legal obligation, within the statutory activities of flood protection institutions, to implement guidance documents prior to the works on the municipality development. It is determined by the local government in the planning documents, which are in accordance with the applicable regulations, acts of local law. Space management, through planning development and land use or the landscape protection, requires the access to comprehensive and reliable information. GIS technology, 3D models and mathematical models using neural networks in spatial analysis and monitoring changes in space to protect flood risk land, give the possibility of collecting the information that constitutes the basis of knowledge on the area, which helps to make decisions regarding a purpose and a method of the land use. The data obtained in this way are a valuable source of knowledge on the stage of preparation of planning documents that determine the directions of municipal spatial development. Under the Act of 27 March 2003 on spatial planning and development [spatial planning and development act 2003], these documents are a municipal study of the conditions and directions of the spatial planning and a local zoning plan.
\end{abstract}

Keywords: municipal spatial planning, local law, development of flood risk areas, sustainable development, GIS, 3D models, neural networks

\section{INTRODUCTION}

Flood or areal flooding risk areas are the priority issues requiring determination of the method and goal of actions within a municipal spatial policy and directions of development. Because of the possible socio-economic effects, the issue requires the decisions that supported with arguments, as well as the awareness and the acceptance of the concerned local community.

One of the basic tools for affecting a municipal spatial policy, in accordance with the act on spatial planning and development, is a study of the conditions and directions of the spatial planning. The local land-use plans are created based on the above-mentioned docu- ment which, according to the act is not a local law. Land use is determined by local plans. They represent local law.

One of the principles of creating a local municipal law, in accordance with the legal-administrative procedure, is to include the local community at the initial stage of the document implementation and at the stage of consultation while proceeding with the project document. The aim of the local community participation is, according to the legislator, the adoption of the law, the effects of which shall be accepted by the community.

Therefore, it seems that in reference to the problematic areas, including the areas exposed to floods or areal flooding, the awareness of economic and social consequences of adopting 
certain solutions, is the primary argument. Such reasoning suggests the need to inform and raise awareness among the local community, where these issues are concerned. That means residents and potential investors.

\section{LEGAL STATUS}

In accordance with the applicable laws, flooding protection is the task, inter alia, of governmental and local administration [Water Law Act 2017]. Flood protection is carried out considering the flood risk maps and flood risk management plans. For river basin districts, according to the art. 167 of the Water Law Act, a preliminary assessment of the flood risk is prepared, on the basis of the available information, including the impact of climate change on the occurrence of floods. This document includes the maps of the river basin districts, indicating the boundaries of river basins, watersheds, coastal belt and basin boundaries, and showing the topography of the terrain and its development. The preliminary assessment also points to the potential negative effects of flooding, which may occur in the future, and may have negative consequences on the life and health of people, the environment, cultural heritage and economic activity. It takes into account: topography, location of watercourses, the effectiveness of the existing water tanks and other flood protection constructions, location of the inhabited areas and the location of areas where economic activity is performed. As far as possible, a long-term development forecast is indicated, in particular including the impacts of climate change on the occurrence of floods and defining the areas exposed to flooding.

The areas of major flood risk, in danger of flood or areal flooding are listed in the preliminary flood risk assessment (PFRA). It is one of the planning documents required by Directive 2007/60/EC of the European Parliament and of the Council of 23 October 2007 on flood risk assessment and its management [Directive 2007/60/ EC 2007]. The implementation of the above, in accordance with the Water Law Act, is the responsibility of the Polish Water authority. The preliminary flood risk assessment was to be developed within the "IT system of the Country's Protection Against Extreme Harazds (ISOK)" project. It has not been finished yet.
However, it should be noted that the maps of the initial flood risk (Fig. 1., Fig. 2) assessment present results in very small scales, i.e. 1:250000, $1: 300000,1: 350000$. On the other hand, the aim of PFRA is not a precise determination of areas at risk of flooding, but rather an initial identification, in order to select the rivers that generate the flood risk. In accordance with the legislator's assumptions, mathematical hydraulic models are scheduled to be created [flood hazard regulation 2013] for the rivers indicated in the preliminary flood risk assessment. In this way, precise areas will be designated and presented in the flood risk maps. Those areas are expected to be the basis for spatial policy on flood risk areas [Program - raising public awareness 2012].

\section{MUNICIPAL PLANNING DOCUMENTS}

On the basis of the article 166 paragraph 1 of the Water Act, in order to protect people and property against flooding, the areas of major flood risk are taken into consideration in:

- the concept of the national spatial planning,

- a voivodeship zoning plan,

- a general metropolitan study of the conditions and directions of the spatial planning,

- a municipal study of the conditions and directions of the spatial planning,

- a local zoning plan,

- a municipal regeneration program,

- a decision to establish the location of public investments,

- a decision on land development and management conditions.

The level of flood risks, resulting from the designation of major flood risk areas is taken into account in the decisions on the location of public investments and in the decisions on land development concerning the real estates situated, fully or in part, on the land that the flooding problem relates to or may relate to [Water Law Act 2017].

According to the act on spatial planning and development, a municipal study of the conditions and directions of the spatial planning should take into account major flood risk areas (Fig. 3, Fig. 4). Transitional regulations, which consider the circumstances under which flood risk maps do not indicate any areas on, cause difficulties. They result from the fact that since 


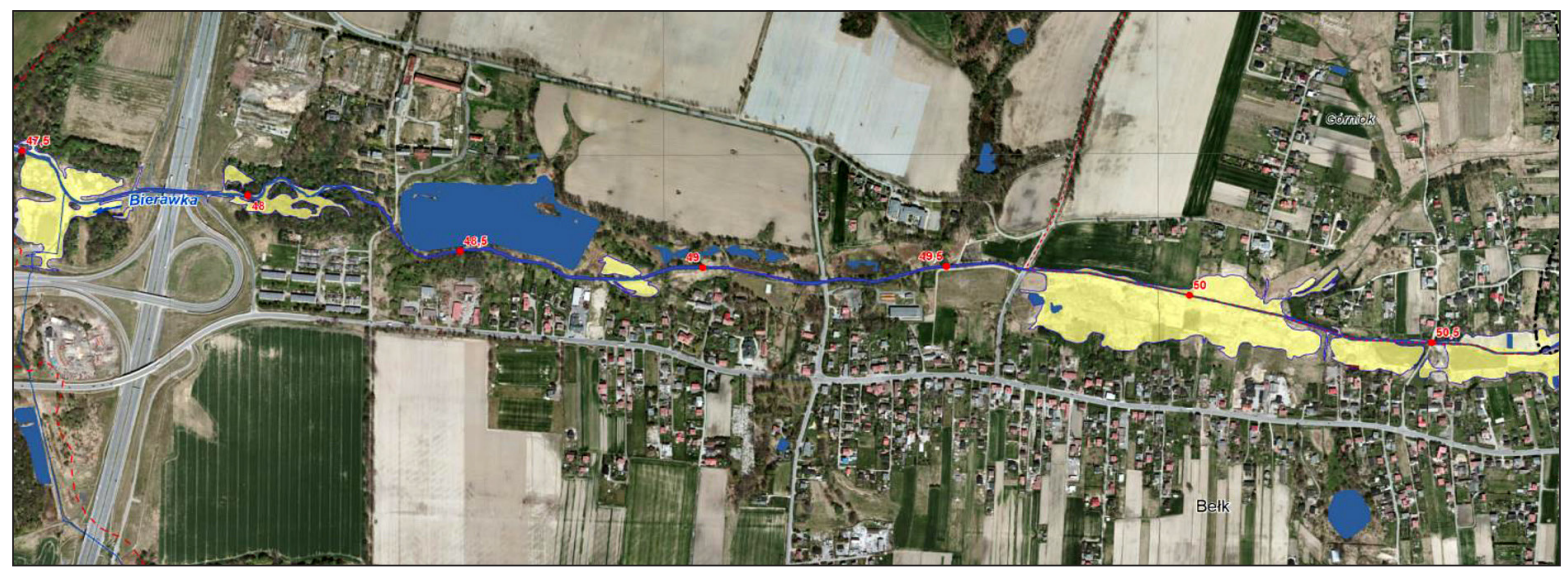

Fig. 1. Flood risk map - the value of potential losses. Source: IT System of Country Protection

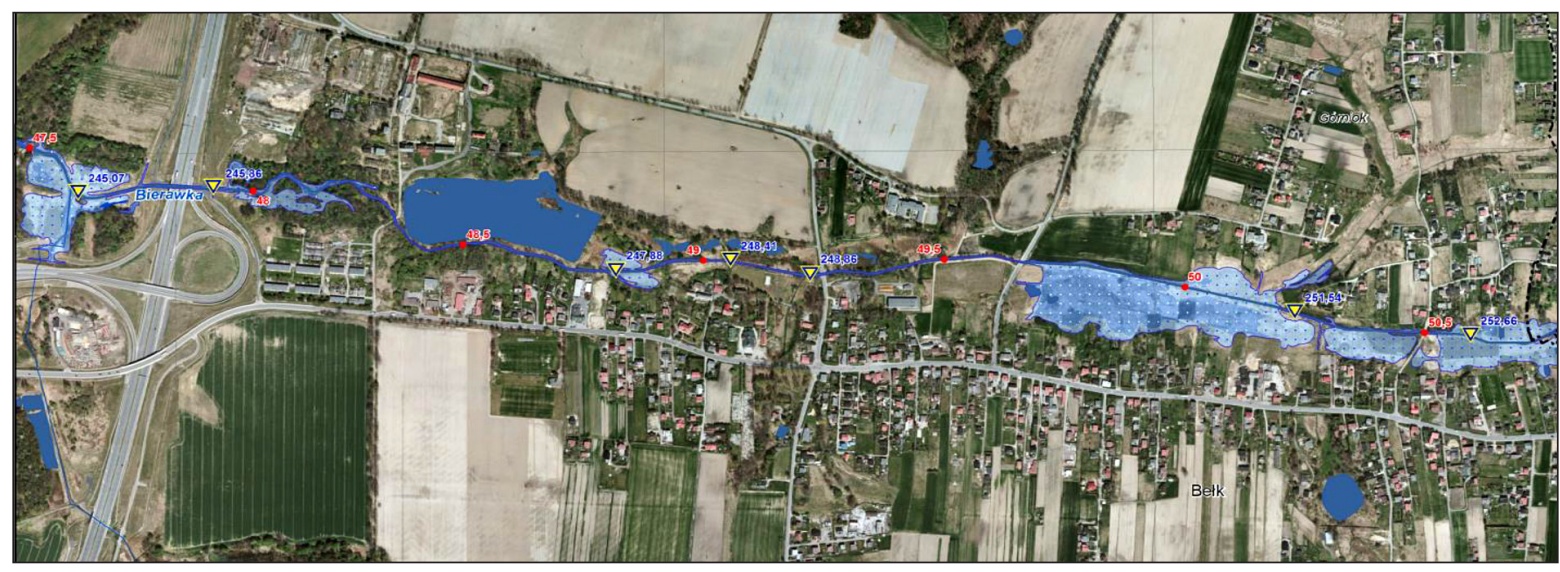

Fig. 2. Flood risk map - the depth of water. Source: IT System of Country Protection

the adoption of the target documents, determining the flood risk areas has been supported by the studies of flood protection. These studies were carried out by the appropriate regional director of the Regional Water Management Board. Formally, these documents are not the basis for determining the boundaries of land at risk of flooding. Introduction of local plan findings or a study of the conditions and directions of the spatial planning on their basis is associated with the implementation of local laws - in this case, the local plan, based on legally unjustified, then faulty documents. Independently, the following documents can be considered as a support while determining flood areas: the sozologic (environmental protection) map of the State Geological Institute, the map of areas at risk of areal flooding in Poland of the State Geological Institute, or the information available in the websites, including geoportals. However, just as in the case of flood protection studies, there is no legal basis for the local plan to be based on their findings.

\section{GIS TECHNOLOGY - 3D MODEL}

Due to the development of GIS technology, its use in spatial policy and space management system, including the determination of ways to develop and use flood risk land seems inevitable. Implementation of the zoning plan, limited only to legalizing new investment should be in the present state of knowledge, treated as the abuse in relation to the public space owned by its users, i.e. the residents. Perception of an object due to its relationship with the environment, mainly through the financial implications related to the execution of a planning document, should be one of the elements affecting the location decision. The analysis of spatial effects and aspects of certain investments regarding financial or social consequences (the cost of running cities, the efficiency of infrastructure, especially transport, conditions for investment and running companies or, in other words, well-being and workplace, the cost of flooding impact), using GIS (3D) models becomes a tool helpful in choosing the best option of space development (Fig. 5). 


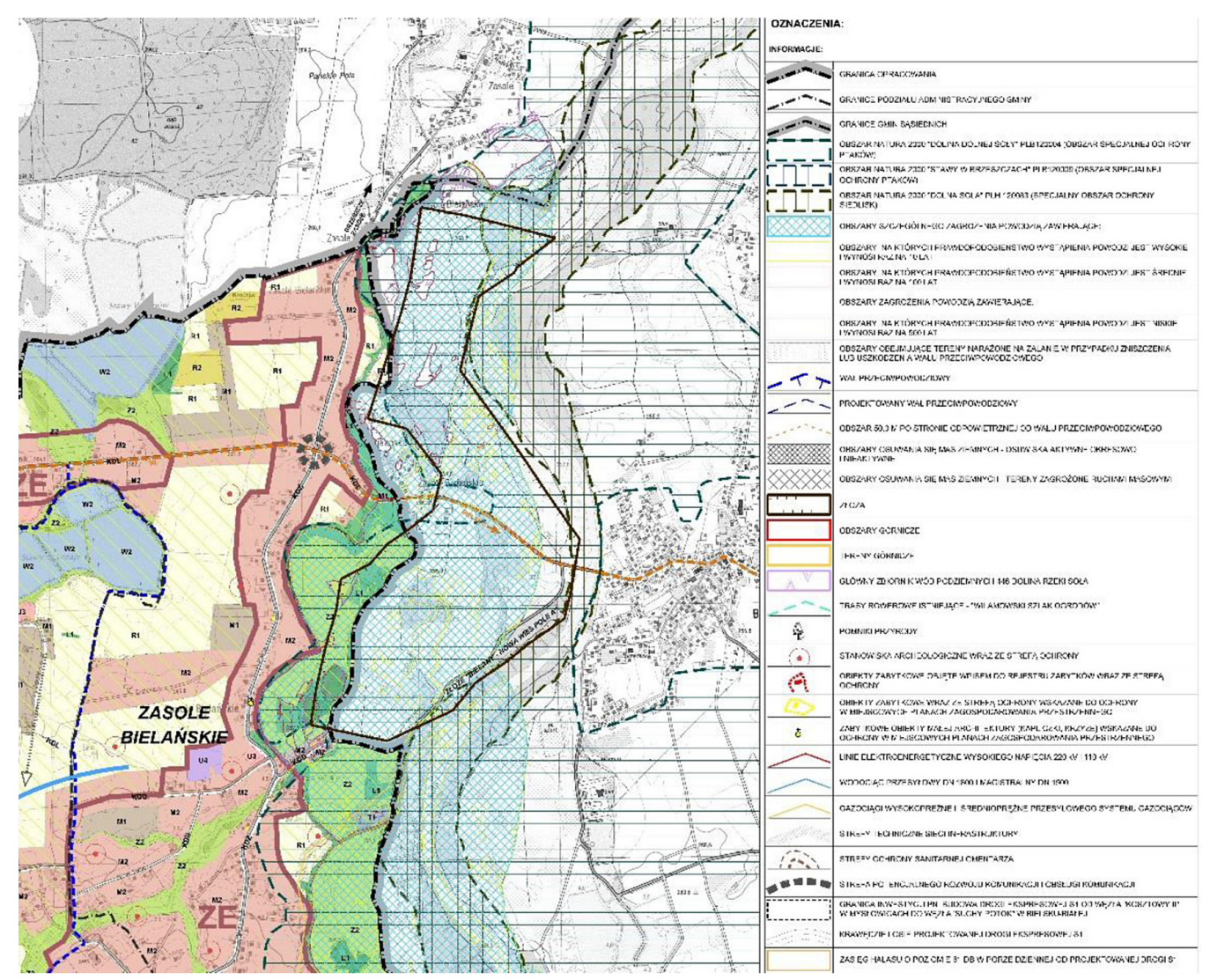

Fig. 3. A study of the conditions and directions of the spatial planning for Zasole Bielańskie in Wilamowice municipality, Silesia Province [P.A. Nova Gliwice S.A.]

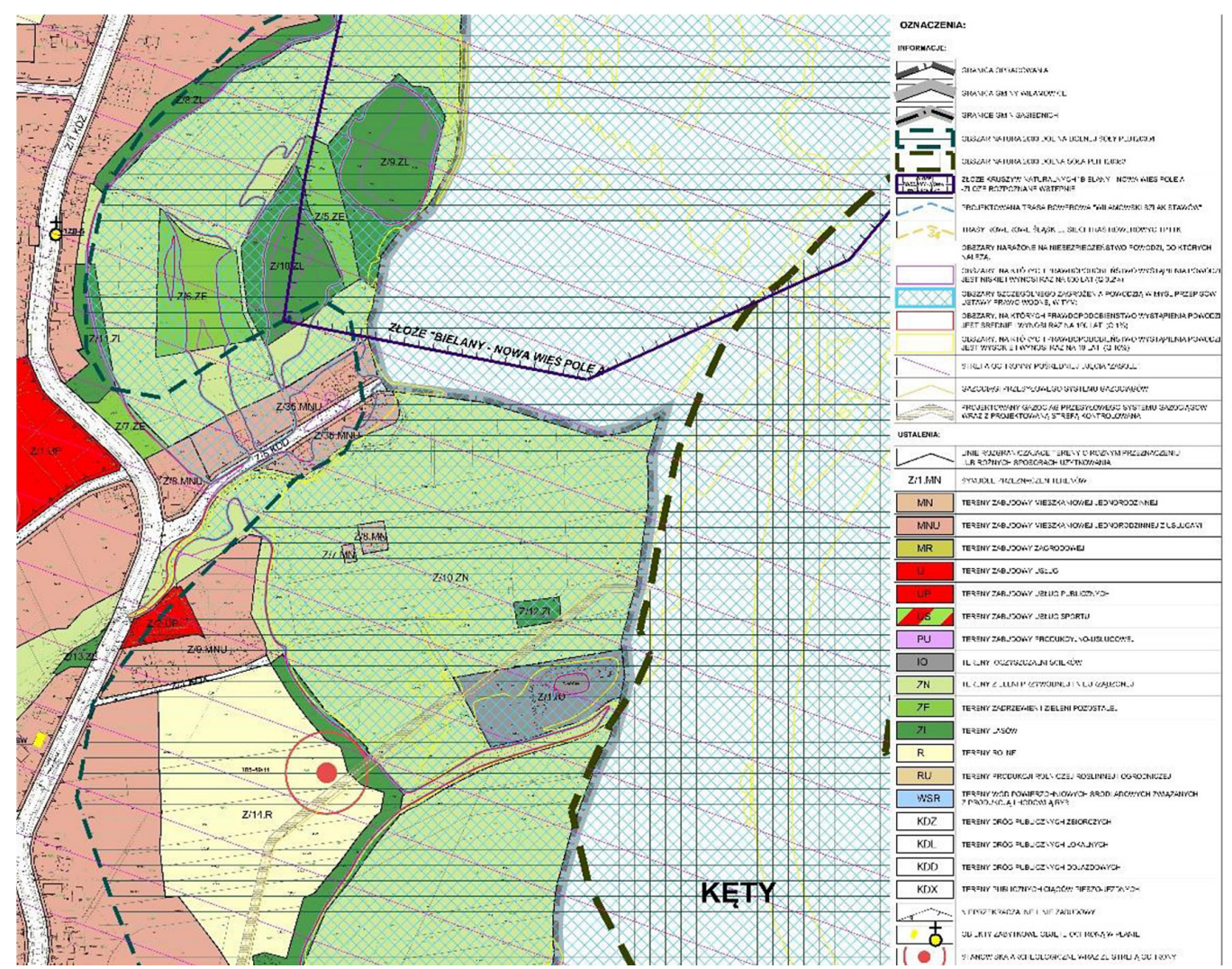

Fig. 4. Local Zoning Plan-Zasole Bielańskie, Wilamowice municipality, Silesia Province [P.A. Nova Gliwice S.A.] 
Local law, also regarding municipal spatial policy, is next to common law, the most important tool. In order to ensure the effectiveness of these activities, it is necessary to accept that the public interest, and thus the element of sustainable development is one of the fundamental objectives of the municipality. Such attitude indicates the need for an extension of the social participation and involvement in the processes of creating a local law in the name of protection of common interests, that is, the local identity. In this case, the use of the GIS model (3D) through presentations, data generation, processing and sharing of the analyses results (Fig. 5) offers great possibilities with regard to a problem of social participation and understanding the complexity of decision- a)

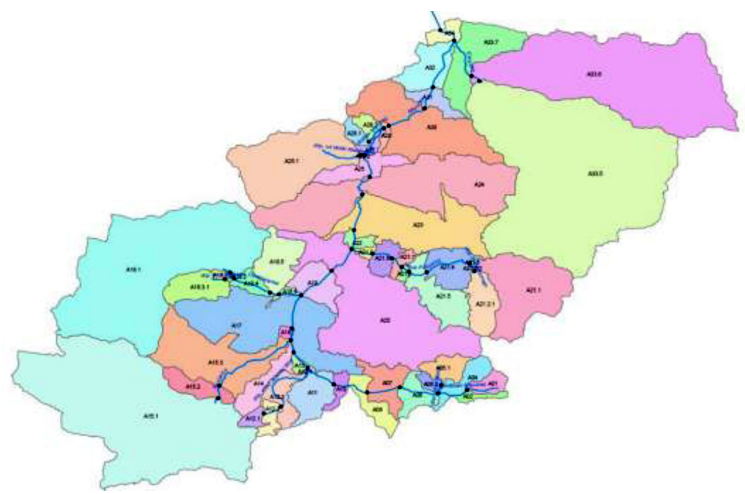

c)

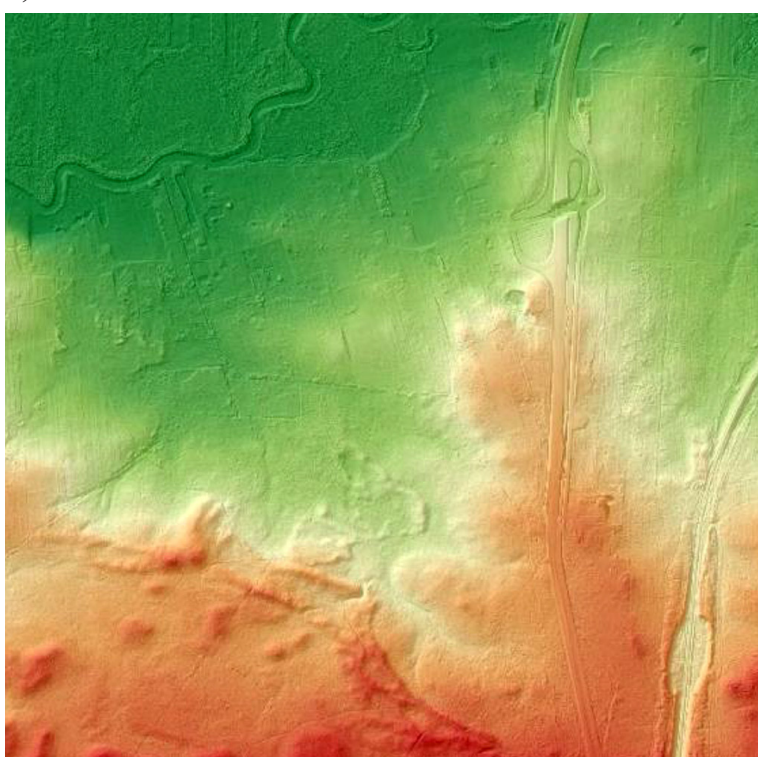

e)

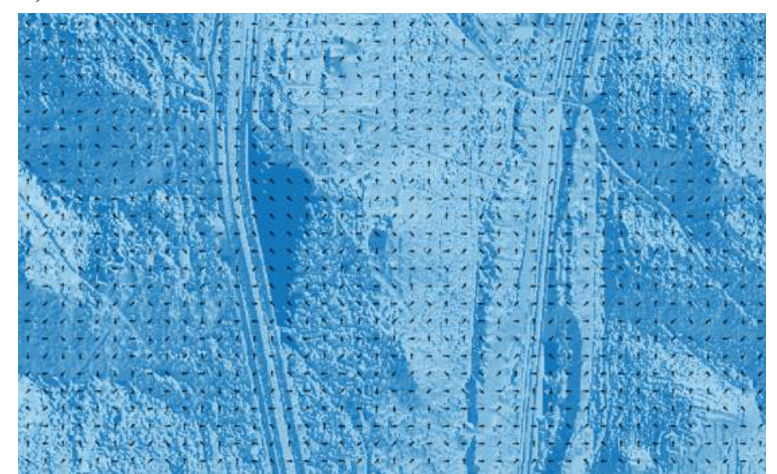

b)

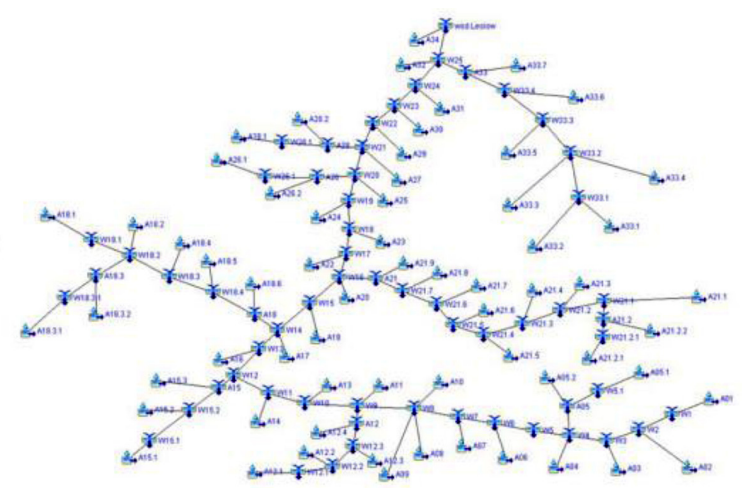

d)

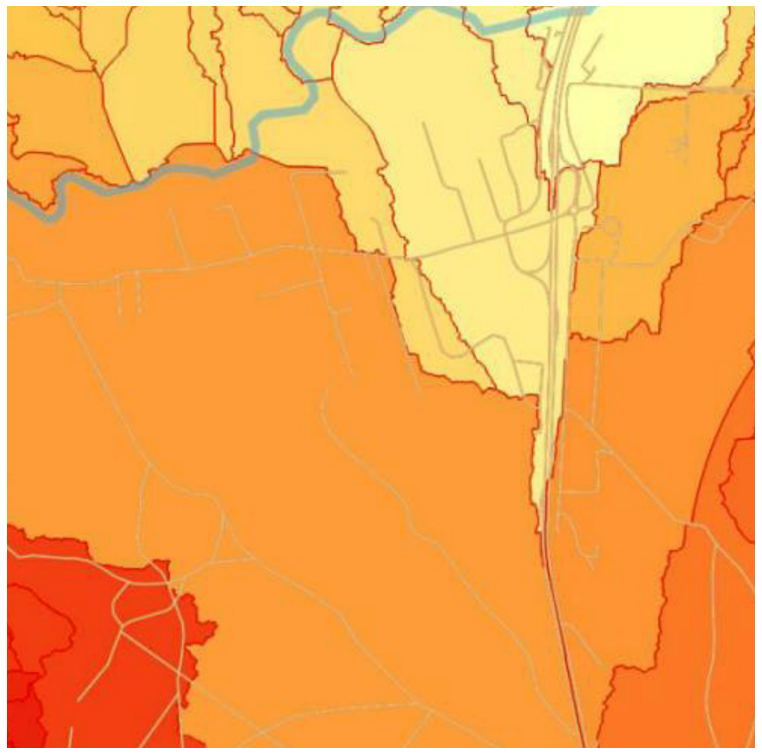

f)

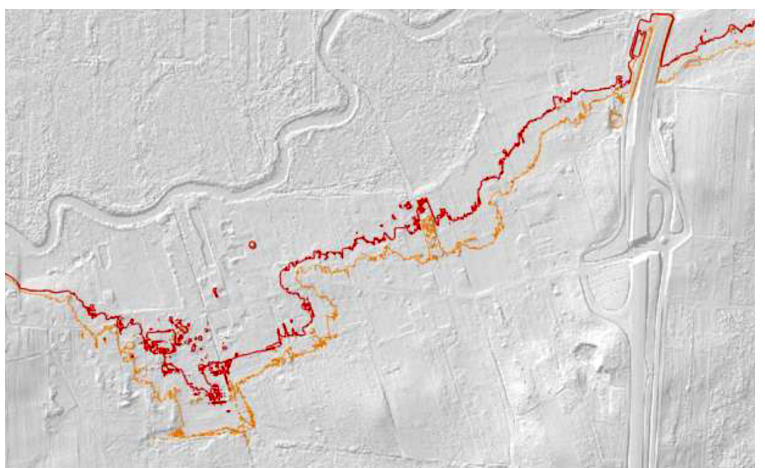

Fig. 5. GIS and mathematical modeling in water management [J. Bobrowski, AquaRD sp. z o.o. , 2015] 
making. This is a vital element of proceeding a range and ways to determine the land use, as its consequences directly impact the economy of the municipality [Bazan-Krzywoszańska 2018].

It must be assumed that a local zoning plan, as a local law, can be a tool pointing the directions of a municipal spatial development supported with analyses, simulations and models that visualize in space problematic decisions, e.g. on the location of investments at flood risk areas. These actions are independent from the applicable law, provided that they are preceded by the efforts to identify conditions and conclusions of the analyses carried out to optimize land use regarding the place traditions and the needs of the inhabitants, as well as the relationship between the urban structure and the surrounding undeveloped land will be shaped with the logic of spatial systems [BazanKrzywoszańska et al. 2016]. The development of measurement techniques that enable quick visualization of 3D model data, in this case, individual buildings and spatial elements, and linking them with the descriptive databases in order to determine flood risk areas, makes it a helpful tool in spatial planning at the so-called smart municipal development [Miller and Hoel 2012, Gue et al. 2013, Bielak 2014].

- Diagram of Radom drainage basin

- The balance of Radom drainage basin

- DEM

- Drainage basin

- Flow directions

- Water floods

\section{METHOD}

Modeling the decision-making issues involves a series of steps to make a set of relevant decisions mapped on a set of benefits, taking into account the conditions which are important to a decision maker, also known as the states of the outside world [Juszczyk 2010]. The models of decision-making issues, depending on the model kind, can be built and solved using differential calculus, linear and nonlinear programming, methods of probability and mathematical statistics, game theories, fuzzy systems and fuzzy neural networks.

Among the available methods to support the decision making process, there are the techniques based on artificial intelligence, in particular, neural networks and neuro-fuzzy systems. The issues like socio-economic decision making, spatial planning or floods prevention are particularly well suited for the analysis of the application of artificial intelligence, due to the key role of the human.

The existing water resources play a crucial role in all locations, at the same time, they are difficult to analyze and make optimal decisions and solutions. This is due to the fact that their values are not always clearly defined and they have many economic, political and social aspects [Szewrański et al. 2018]. Therefore, the neurofuzzy system by Takagi-Sugeno-Kan was used in the presented work to analyze the potential and risks of the land use (Fig. 6).

In order to perform the analysis of the potential and risk of development of a flood risk land,

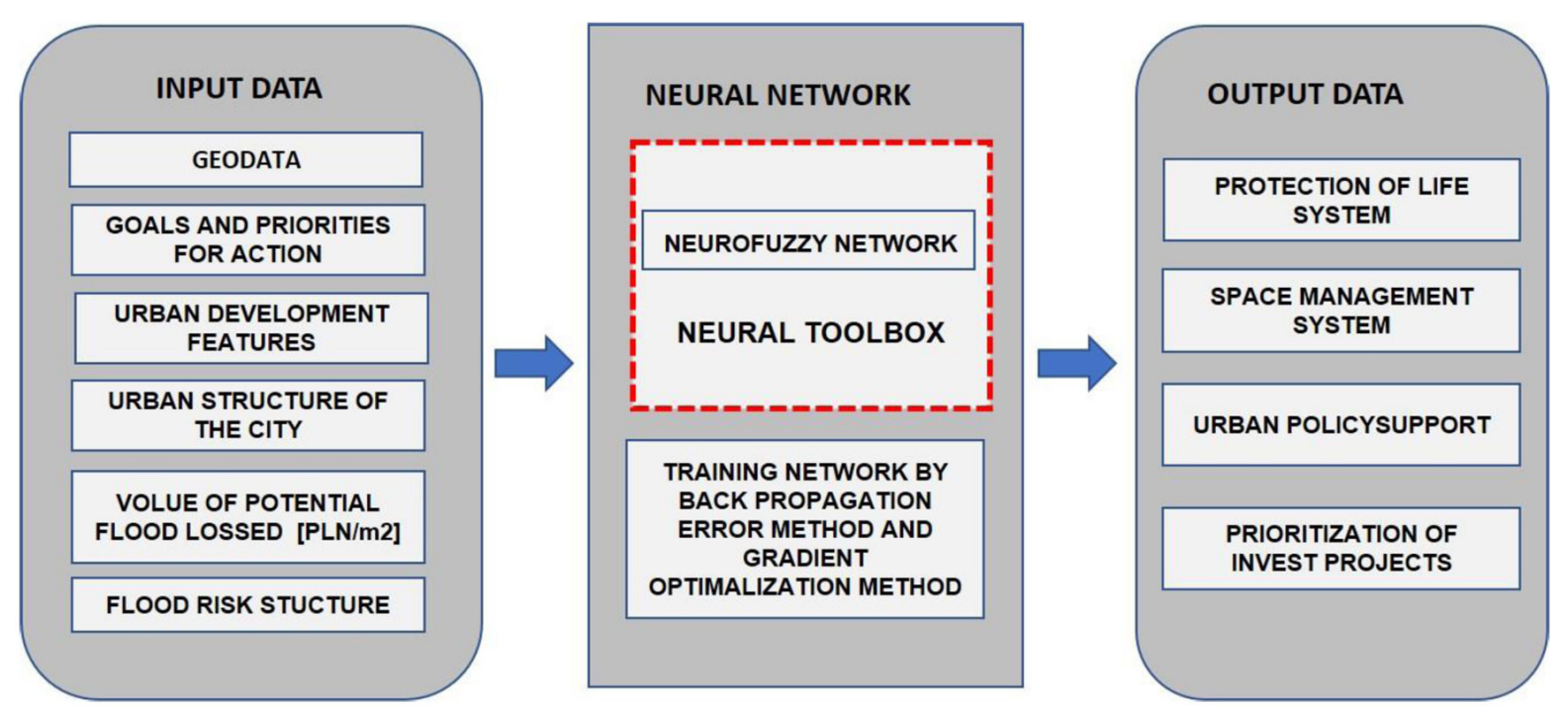

Fig. 6. Analysis of the land use potential and risk 
a model was built which consists of the following elements:

- the input stage, comprising the geodata obtained from digital elevation model, orthophoto, diagonal photos, LoD1, mesh 3D, LIDAR $20 / \mathrm{m}^{2}$, maps of river basin districts (boundaries of river basins, drainage basins boundaries and coastal belt boundaries, topography and the terrain development. Additionally, the analysis was supplemented by the information about the location of residential areas (detached houses or multifamily), areas of economic activity, development free areas, flood risk areas;

- the decision, which concerned the economic impact of the decision to carry out investments in flood risk areas or floodplains,

- the output stage, which should presumably give the answer that allows making decisions about the land use as to minimize the level of damages and losses resulting from a possible flood (Fig. 6).

With a model built in such way, we will search for optimal levels of investment for the region $t$ $(t=1 . n)$ defined by its center so that:

$$
P I_{\text {opt }}=\max _{t_{1} \ldots t_{n}}\left\{\left|C_{1} \bigwedge \ldots \bigwedge C_{n}\right| \bigwedge \bar{G}(n)\right\}
$$

where: $C_{i}-$ membership function specified individually for a center of region $t$

$G_{i}-$ membership function at the output stage.

The above-mentioned model can be extended to any of the parameters and limitations, such as a limited budget or a restriction on the total number of investments in the region. Using the presented way, based on disjunction and estimation procedures with the use of neuro-fuzzy systems, we are able to identify regions with the optimal investment, taking into account the need to minimize damage arising from flood. The analyzed regions can be divided into any number of classes, with a specific level of investment, for example no investment, low, medium and high level of investment.

\section{RESEARCH RESULTS}

The use of a mathematical model, in this case a neuro-fuzzy system, in advance analyzes, making a decision on the purpose of areas endangered by flooding or flooding for investment, gives an- swers to the questions in which areas are possible to achieve their most optimal use. The analysis of the research results indicates the direct dependence of the results obtained in modeling on the type of data used for modeling, their details, accuracy and the level of damage that should be expected, selecting for the development of zones - classes of areas, in the commune space.

Another effect of this type of activities is the space model, to which the attributes describing it were assigned. Visualization of the analysis results gives the possibility of presenting these materials to the interested parties. The explanation whether the interpretation of particular technical or technological issues with the help of such constructed data sets becomes an extremely helpful tool in the decision-making system (Fig. 7).

\section{DISCUSSION}

Decision-making in space management policy requires an integrated and cross-sectoral approach to the problem. The idea is to capture the complexity of systems mutually affecting each other. Important decisions, also in terms of environmental impact, may be taken with the use of knowledge from different fields [Olazabal et al. 2018]. The preparation of space management systems requires an understanding of its complex structure and responding to individual factors directly or indirectly affecting its operations. Gathering knowledge into bases enables an attempt to understand the processes affecting the system. The use of mathematical models makes creating such knowledge easier. The methodology for socio-economic modeling systems, such as a flood hazard prevention system related to a municipal land management policy, indicates the need for an integrated approach to modeling [Elsawah et al. 2017]. Regardless of the economic system, implementation of the local policy objectives requires a great attention to social acceptance. Commitment and understanding the issue gives a chance to the appropriate approach to recommendations or decisions, sometimes controversial, concerning municipal land use [Wolfe 2008]. The analysis of links between the various criteria which impact the decision gives the chance to identify the impact of each of them on the others, thus enabling to influence the efficiency and effectiveness [Arvan et al. 2016]. Given the complexity of the dependencies and the number of factors affecting 


\section{MUNICIPALITY}

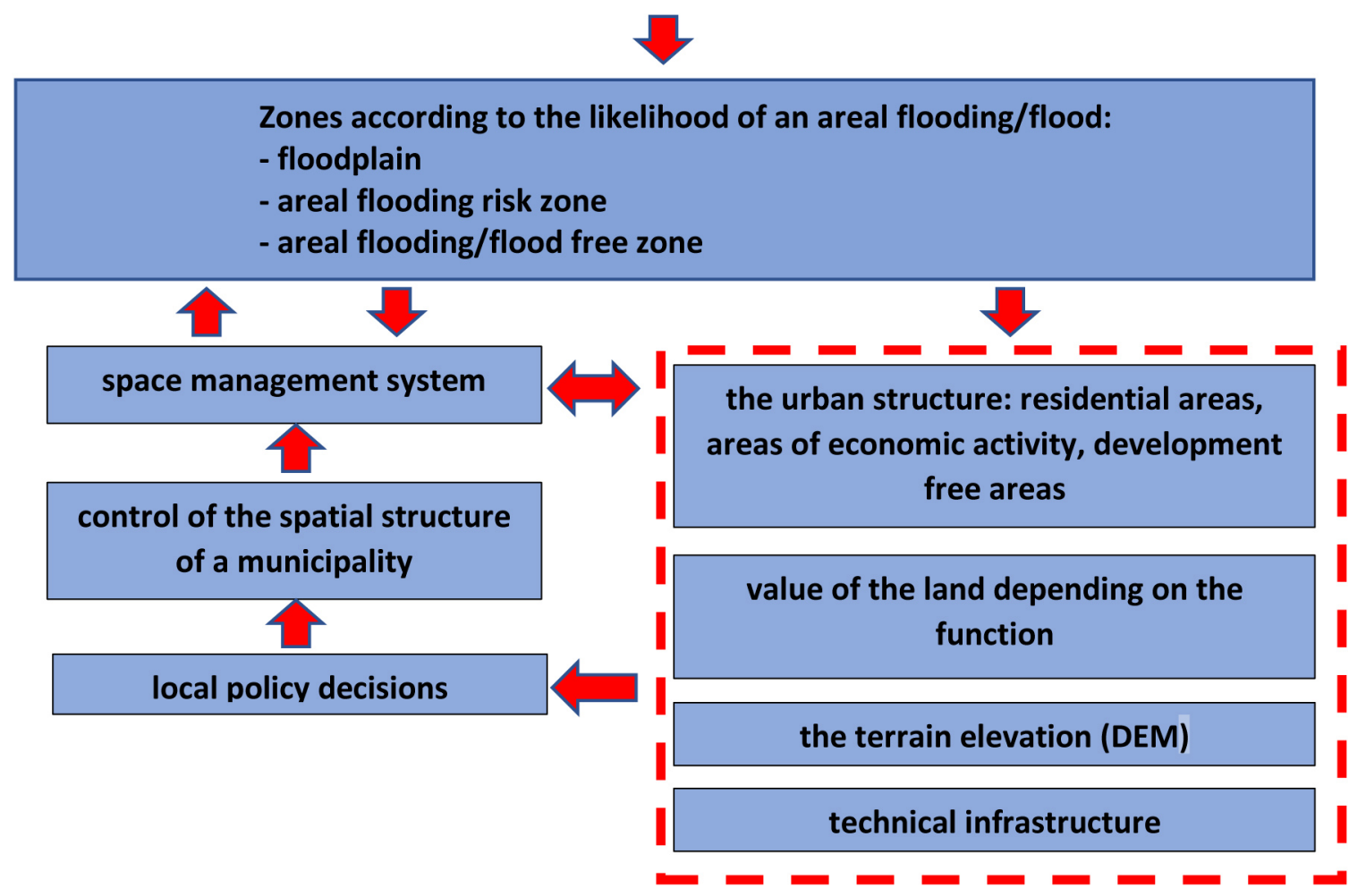

Fig. 7. The application of mathematical model for decision concerning investment decisions on the floodplains of the municipality

the final decision due to the effects, it seems that the mathematical models, which support decisions and have impact on effective forecasting the results of the process-shaping activities, are appropriate [De Mario et al. 2017]. Analyzing the satellite images along with the digital elevation model DEM, gives the possibility of scenarios depicting certain issues that impact the identification of floodplains. In this case, using mathematical models and dedicated classifiers yields quite good results [Singh and Singh 2017]. The scenarios that indicate the potential impact of changes in water flow in relation to the arising threats are also very important, due to the predictability of storm-water control.

\section{CONCLUSIONS}

Spatial policy of the municipality, in terms of the development directions, should be clearly identified in the document - a municipal study of the conditions and directions of the spatial planning. According to the intention of the legislator, it includes spatial issues and socio-economic development program in its findings. The study takes into account the basic elements of spatial planning and presents the policy directions with regard to the elements of the protection of the environment, the landscape or land, which is implemented to the local municipal plans.

The main task of the study should be to coordinate the protection and investment plans of all public administrations. The findings of the study should apply to all public administration bodies in the municipality, not only the services responsible for the implementation of spatial policy. Such policy allows to link the goal, i.e. new investments considering the results of the interdisciplinary assessment of land-use options (variants), carried out with the local community participation, with the analysis of the potential and risk of the land development, including the analyses by $3 \mathrm{D}$ models and mathematical models, for example neuro-fuzzy system, as research tools helpful in justifying the decisions of the municipal authorities. Raising the public awareness of threats in spatial management at flood risk areas and their socio-economic effects determines the cost of the functioning of the cities, the efficiency 
of the infrastructure, especially transport, investment conditions and the functioning of business, i.e. well-being and workplaces.

\section{REFERENCES}

1. Arvan M., Omidvar A., Hodsi R. 2016. Intellectual capital evoluation using fuzzy cognitive maps: scenario-based development planning, Expert Systems With Applications, 55, 21-36.

2. Bazan-Krzywoszańska A. 2018. GIS technology as a tool for protecting landscape and cultural values in spatial planning, Structure, 129-137.

3. Bazan-Krzywoszańska A., Mrówczyńska M., Skiba M., Łączak A. 2016. Economic conditions for the development of energy efficient civil engineering using RES in the policy of cohesion of the European Union (2014-2020). Case study: the town of Zielona Góra, Energy and Buildings, 118, 170-180.

4. Bielak S.R., Application of mathematical modeling in the analysis of river water flow conditions (in Polish). http://www.sebastianbielak.pl/uploads/pdf/Aura\%20nr\% 201\%20(2014).pdf, [access: 13.06.2018].

5. Bobrowski J. 2015. The use of GIS and mathematical modeling in water management (in Polish). AquaRD sp. z o.o., http://www.knyszyn.bialystok. lasy.gov.pl/documents /62684/28334384/prezentacja_oswos jb.pdf/15f23543-1ac0-46dc-b2df31618a9e9659, [access: 13.06.2018].

6. De Mario C., Fenza G., Loia V., Orciuoli F. 2017. Neurocomputing, 256, 35-48.

7. Directive $2007 / 60 /$ EC of the European Parliament and of the Council of 23 October 2007 on the assessment and management of flood risks (Off. J. of EU L 288 of 06.11.2007).

8. Elsawah S., Pierce S.A., Hamilton S.H., van Delden H., Haase D., Elmahdi A., Jakeman A.J. 2017. An overview of the system dynamics process for integrated modeling of socio-ecological systems: Lessons on good modeling practice from five case studies, Environmental Modelling \& Software, 93, 127-145.

9. Guo R., Li L., Ying S., Luo P., He B., Jiang R.
2013. Developing a 3D cadastre for the administration of urban land use: A case study of Shenzhen, China, Computers, Environment and Urban Systems, 40, 46-55.

10. Juszczyk M. 2010. Modeling the costs of residential buildings with the use of artificial neural networks (in Polish). Czasoposmo Techniczne - Technical Transactions, 2, 167-175.

11. Miller J.S., Hoel L.S. 2012. The "smart growth" debate: best practices for urban transportation planing, Socio-Economic Planning Sciences, 36, 1-24.

12. Off. J. 2013.0.104 - the Regulation of the Minister of the Environment, the Minister of Transport, Construction and Maritime Affairs, the Minister of Administration and Digitization and the Minister of Internal Affairs of 21 December 2012 on the development of flood hazard maps and flood risk maps.

13. Olazabal M., Chiabai A., Foudi S., Neumann M.B. 2018. Emergence of new knowladge for climate change adaption, Environmental Science and Policy, 83, 46-53.

14. Program of activities aimed at raising public awareness of threats related to the spatial management in the flood risk areas and the rules of town planning and construction resulting from them, Institute of Spatial Management and Housing in Warsaw, Warsaw 19.09.2012.

15. Singh K.K., Singh A. 2017. Identyfication of flooded area from satellite images using Hybrid Kohonen Fuzzy C-Means sigma classifier, The Egyptian Journal of Remote Sensing and Space Sciences, 20,147-155.

16. Szewrański Sz., Chruściński J., van Hoof J., Kazak J.K.,Świader M., Tokarczyk-Dorociak K., Zmuda R. 2018. A Location Intelligence System for the Assessment of Pluvial Flooding Risk and the Identification of Storm Water Pollutant Sources from Roads in Suburbanised Areas, Water, 10 (6).

17. The Act of 20 July 2017-Water Law (Off. J. of 2017 items 1566, 2180, of 2018 items 650, 710).

18. The Act of 23 March 2003 on spatial planning and development (Journal of Laws of 2017, item 1073, 1566).

19. Wolfe J.M. 2008. Reinventing planning: Canada, Progress in Planning, 57, 207-235. 